\title{
How the professionals can identify needs for improve- ment and improve Food Distribution service for the home-living elderly people in Sweden - an action research project
}

\author{
Zada Pajalic $^{1}$, Kirsti SkovdahI ${ }^{2}$, Albert Westergren ${ }^{1}$, Lena Persson ${ }^{1}$ \\ 1. The School of Health and Society, The PROCARE Group \& The Network for Eating and Nutrition, Kristianstad University, \\ Sweden. 2. The School of Medical and Health Sciences, Örebro University, Sweden.
}

Correspondence: Zada Pajalic. Address: Kristianstad University, Elmetrpsvägen 15, 29188 Kristianstad, Sweden. Email: zada.pajalic@hkr.se.

Received: October 30, 2012

Accepted: December 9, 2012

Online Published: J anuary 22, 2013

DOI : $10.5430 /$ jnep.v3n8p29

URL: http://dx.doi.org/10.5430/jnep.v3n8p29

\section{Abstract}

Background: Making changes to municipal social care and service has been found to be challenging to realise and highly multifaceted. The aim of this study was to describe how the professionals can identify needs for improvement and improve Food Distribution (FD) service for the home-living elderly people in Sweden.

Methods: This study is part of a larger project with an action research approach focusing on to municipal FD to older people living in their own home in Sweden. The professionals involved in FD invited the first author to assist them in this process. The study participants were comprised of the following groups: "The Identification focus group" that identified need for improvement of FD ( $\mathrm{n}=5)$; "The Action focus group" that planned and choose suitable 'action' for improvement $(n=5)$; "The First Evaluation group" $(n=4)$ that evaluated the content of planned improvement and finally "The Second Evaluation group" $(\mathrm{n}=29)$ that evaluated the changes following improvement. The data was gathered and analysed by Story Dialogue Method.

Results: The need to update and increase the FD recipient's knowledge in nutrition by sending them informative letters was found to be an important area to focus on. The information letters $(n=1700)$ were distributed to the all FD recipients in six municipalities in southern Sweden during April 2011. The results were evaluated during May 2011. The overall general estimation was that the content of the letters indicated that this was a suitable method for gaining information to make a nutrition competence update. Following this, "The Action focus group" decided: firstly, to continue preparing and distributing information letters to all FD recipients to be sent out twice a year, and secondly: to make the information letters accessible on the websites of the six municipalities and county councils involved.

Conclusions: This study showed that systematic work inspired by an action research approach with motivated and involved participants can be beneficial and a starting point for the process of change in municipal service and care practice. The major conclusion of the study was that systematic reflection over everyday practice can be the vehicle for the future change of practice. The research process and the findings have implications for nursing, care of the elderly and gerontology. 


\section{Key words}

Action research, Evaluation, Improvement, Food distribution, Story dialogue method

\section{I ntroduction}

Making changes to municipal social care and service has been found to be challenging to realise and highly multifaceted ${ }^{[1]}$. In the present study, an action research (AR) approach was chosen to address the issues the participants had decided to work on in the real world of practice. Further, an AR focus on development and changes of practice in order to obtain knowledge about how these changes could be performed and what would be going on during the process. The central issue in AR is that those involved in a change process may ask questions to the practicing professionals and thereafter produce an action plan. It is a relation between action and the understanding of what is taking place. Through this relation the AR inspired process appears to be a way for all those involved who have an interest in releasing existing practice from its own preconditions. With this in mind we have described the part of the work with food distribution (FD) where we involved the staff and food recipients in order to improve their knowledge related to nutrition.

\section{Background}

Municipal FD for older people living in Sweden is an organisation specific to Swedish municipal care and service and may be compared to the international concept of "Meals-on-wheels" ${ }^{[2-4]}$. The purpose of the Swedish FD organisation is to distribute prepared meals to elderly people living in their own home and even other citizens with health related impairments who have difficulties preparing their own food and cannot meet this need in any other way. The prepared meals are mostly in the form of a lunch which is distributed daily as a warm meal (60 degrees) or weekly as a cold meal ${ }^{[5]}$. In Sweden, all municipalities have been responsible for the care and service for home-living elderly people FD since 1992 following the introduction, by the government, of a care system known as the "Ädel reform 1992". The overall aim of the this reform was to offer elderly people care and service in their own homes for as long as possible, even if they have extensive needs. FD, as part of the municipal care and service, is regulated by two legislation parts: the Social Services Act of 1981 and the Health and Medical Care Act ${ }^{[6]}$.

Each individual municipality may organise their FD service based on their own circumstances since there is no legislation that regulates the service in detail ${ }^{[6,7]}$. In Sweden, FD is a legislative right for all citizens requiring this type of assistance and is financed through public funds. FD is to be accessible based on the principles of need and solidarity ${ }^{[8]}$. The system automatically comes into operation at the point in time when an elderly person, or in special cases a younger person, is no longer able to prepare their own food and their needs cannot be met in other way ${ }^{[9]}$. The FD service in Sweden is a complex organisation involving hierarchal decision making at several levels, including the top decision-makers in the community. That is to say politicians, committees and civil servants in the administration, such as public home care officers, diet managers, and team managers. Also involved are the food producers. Often the food is prepared and packed at a municipal kitchen. The food distributors are mostly assistant nurses and taxi drivers ${ }^{[2-4]}$.

Improving a social and care service such as FD often requires a combination of improvements within the organisation and the encouragement of the involved personnel ${ }^{[10]}$. Even engagement by the FD receivers is important for the improvement process, as it is they who can contribute with their everyday experiences and with what they consider is important to change ${ }^{[10]}$. Improvement of practice by using an AR approach enables all those involved to address the issues that they have decided to work on within the real world of practice ${ }^{[1]}$. The AR approach assumes that personnel who are involved in an improvement process have unique experiences related to their own practice, and that they know what works and what does not ${ }^{[11]}$. All of the participants in this study had extensive and unique experiences related to the FD service in Sweden. The AR approach is dependent on the willingness and motivation level of the participants. Indeed, motivated participants are a precondition and the key to successful practice improvement ${ }^{[12]}$. 
Making changes to a municipal social and care service has been found to be problematic to achieve and highly complex ${ }^{[13]}$. Further, it was shown that the involvement of the various skilled personnel i.e. the personnel involved in the development of home and care practice is beneficial, since these people have unique experiences of the issue in a local context and can focus on the practical problems they face in their daily work and practice ${ }^{[14]}$. Other benefits offered by the involvement of the different personnel is that it promotes collaboration across professional boundaries, which has been shown to be beneficial for care receivers and care and service organisation personnel ${ }^{[15]}$. The most optimal scenario in a practice development process is one where motivated personnel initiate improvements and are active during the AR process ${ }^{[16,17]}$. However, a literature search indicates that this study is necessary contribution to the field. It provides new information about the little-researched issues of how the professionals can identify needs for improvement and improve FD service for the home-living elderly people in Sweden.

The aim of this study was to describe how the professionals can identify needs for improvement and improve FD service for the home-living elderly people in Sweden.

\section{Method}

This qualitative, descriptive study is part of larger research project using an action research (AR) approach ${ }^{[10]}$ to focus on municipal FD services to the home-living elderly people ( $\geq 65$ years) in Sweden.

\subsection{Participants}

The participants, representative of professionals, in this study initiated the improvement process and invited first author (ZP) as participatory action researcher to support them in their improvement process. Further the participants comprised 1) professionals involved in FD; 2) the elderly persons comparable to FD recipients and 3) FD recipients (see Figure 1).

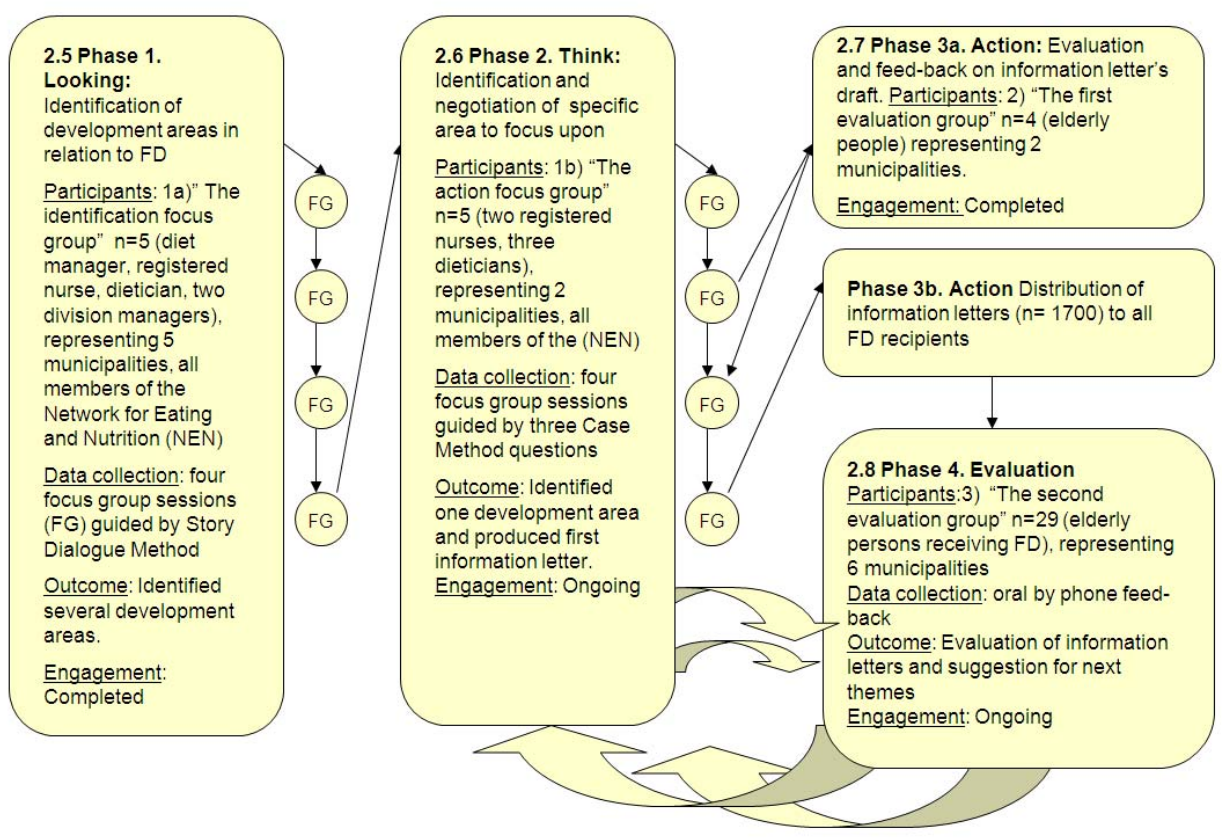

Figure 1. Looking -Think-Act-Evaluation phases with focus on how the professionals can identify needs for improvement of Food Distribution (FD) service for the home-living elderly people in Sweden.

The professionals who comprised 1a) "The Identification focus group" and 1b) "The Action focus group" were all members of The Network for Eating and Nutrition (NEN). 
The NEN was founded in Sweden in 2003 with the purpose of improving and developing all services connected to nutrition and eating by strengthening inter-organisational and inter-professional collaboration and further, to disseminate new knowledge to service and care providers within a local area and to provide national and regional guidelines for practice ${ }^{[18]}$. The NEN included six municipalities in the southern part of Sweden, including two hospitals and primary health care centres. The following professionals took part in the NEN network: registered nurses $(n=16)$, dieticians $(n=8)$, diet mangers $(n=2)$, senior lecturers in nursing $(n=2)$ and division mangers $(n=2)$.

1a) "The Identification focus group" $(\mathrm{n}=5)$ was established during the spring of 2008 with the aim of focusing on FD development. The focus group included; one diet manger, one registered nurse, one dietician and two division managers, all of them NEN members, who all agreed to participate in the group until the spring of 2011.

1b) "The Action focus group " $(\mathrm{n}=5)$ was established in the spring of 2011 with the purpose of continuing the work initiated by "The Identification focus group". This group is still active. The members in this group are two registered nurses and three dieticians, all members of the NEN.

2) "The first evaluation group" comprised of four elderly persons comparable to FD recipients, i.e. potential FD recipients, they were of ethnic Swedish background, all were $\geq 65$ years, and able to communicate both verbally and in writing, using Swedish. Two of them were retired teachers; one was a housewife and one a farmer. This group was established during 2011 and recruited by 1b) "The Action focus group" with the aim of reviewing and evaluating the content and appropriateness of the planned changes in the form of the information letters to be sent to FD recipients. 2) "The First evaluation group" completed their involvement once when had they delivered their viewpoints on the content of the information letters during the spring of 2011.

3) "The Second evaluation group" comprised of FD recipients $(n=29)$ who offered oral by phone feed-back/evaluation of information letters and suggestion for next themes. This number is not final, as when this report was written the possibility to give verbal feedback was still open.

\subsection{The action researcher's role}

The action researcher (ZP) was invited to support the participants, involved in municipal FD, in their work related to the development of this service. Further the researcher's role "to support" was defined as: to facilitate focus group sessions, to contribute with research methodology, to clearly define the issues raised, to offer an outsider's perspective on the issues, to participate in the evaluation of a chosen action, and to give support in the "look, think, act and evaluate phases" of the chosen development strategies ${ }^{[10]}$ and further to document the details related to the process and its outcomes. The intention behind the collaboration was to provide the opportunity to collectively explore the possibilities and reflect on how to implement changes in the FD practice in order to improve the service.

\subsection{The study context}

The project was conducted in six smaller and medium-sized municipalities, totalling about 176000 inhabitants, and all situated in southern part of Sweden. Approximately 1700 elderly people living in these municipalities used the municipal FD service; however, this number could vary, since some recipients only used the FD service on certain days of the week. The meals were produced at municipality owned kitchens. Lunch was the most common meal delivered, which corresponded to $30 \%$ of the recipient's daily nutritional needs. The meal box was delivered personally to the recipient by assistant nurses or taxi drivers and not simply left outside their door.

\subsection{Design}

An AR Approach ${ }^{[10]}$ was chosen for the present study to enable participants to address the issues within the real world of practice which are important for them to focus and work on. Further the AR is research in the context of the practice and has direct relevance to those participating. In this study, the ZP contributed with "outsider" perspective expertise in 
research methodology and facilitation. The participants were the "insiders" of the research team and understood the background, everyday practice and the FD context being studied ${ }^{[10]}$. To motivate participants in a certain way, and to encourage critical reflection, the researcher decided to use the Story Dialogue Method (SDM) ${ }^{[19]}$. SDM as data gathering and analysis method is based on the use of material taken from everyday practice and used as "triggers" to formulate probing questions in dialogical and structured form ${ }^{[19]}$. The SDM and AR are held to be complementary approaches for achieving change. Further these approaches were found suitable as techniques for problem solving, systematic methods to generate data, and to encourage collaboration active participation through dialogue where there are no restrictions in communication and everyone's point of view is considered to be equal ${ }^{[19]}$. Further the SDM fits with AR cyclical phases that influence change through "look, think, act and evaluate". The 'looking phase' focused on gathering the stories, the 'thinking phase' focused on structured analysis of the stories and the 'acting phase' focused on planning changes, implementation, and the 'evaluation phase' focused on the tenability of the action ${ }^{[10]}$. The focus groups in the 'thinking phase' were guided by three consequence analysis questions inspired by the Case Method (CM): What happens if we do nothing about the development area identified? What happens if we do something about it? Which of the identified development areas must we pay crucial attention to? ${ }^{[20]}$. The study design is summarised in Figure 1.

\subsubsection{Phase 1: Looking}

The first stage in this AR study was to explore the realities and context of FD by focus groups sessions with the 1a) "Identification focus group". The focus group sessions were held by the SDM ${ }^{[19]}$ in order to capture the different perspectives and views. The data was collected in four Focus Group (FG) sessions ${ }^{[21]}$. The FG sessions were taperecorded and lasted about 90 minutes.

At the first FG occasion the theme was to share stories related to FD situations that participants identified as being interesting to improve. The participants were encouraged by the researcher (ZP) to make notes (i.e. details from the stories or ideas for questions). The next step was the reflection circle where the participants outlined their immediate reflections on their colleague's experiences together with the whole group. Following this the participants were encouraged to write notes pertaining to the new information they had received. The notes were a basis for further discussion and reflection. The reflection circle was rounded off with a structured dialogue on the topics: What are the areas in the FD chain that can be developed? Why are some areas in the FD chain experienced as challenging? Why are they challenging? Do we have the authority to improve these areas? and how can we go about it?

Three consequence analysis questions inspired by the CM were added ${ }^{[20]}$ : What happens if we do nothing about the identified development area? What happens if we do something about it? Which of the identified development areas must we pay crucial attention to? The participants wrote their insights from the focus group session on the cards. One criterion was that it was worth sharing with other people and included enough detail to be understandable ${ }^{[19]}$. Below is an example of insights cards (see Table 1).

Table 1. Example of written insight cards

Confusion among staff concerning who is responsible for food distribution

No one takes responsibility for the elderly persons' nutritional status

There is no forum for meetings, reflections or dialogue

The organisation is unprepared for new responsibility

Not everyone knows what the dietician's role is

Politicians know about the changes, but this knowledge is lost when the organisation is changed, since new people and new ideas appear

Not everyone is aware of their own role, such as: what do I do when there is a problem?

Clarify the problem and give it priority and status

Politicians are important and should be a part of the whole process 
The fourth FG session started with short summary discussions about the next step in the AR process. All of the cards were placed on the table arranged into common themes. The themes were: the organisation of work, the need for continuous development, the FD recipient's and the professional's competence in nutrition and the collaboration between various professional groups. The 1a) "Identification focus group" announced that they would discontinue their participation in the study due to lack of time and handed over their work to 1b) "The Action focus group".

\subsubsection{Phase 2: Think}

The Action focus group" continued with the 'think' phase of the study. The theme for FG sessions was based on outcomes from the 'look phase'. The FG session was guided by three consequence analysis questions ${ }^{[20]}$. The second FG session resulted in the identification of one area upon which to focus. The third session focused on how to ensure that the content of the information letters was adjusted to the target group. The fourth focus group session focused on the final decision on how the information letters should be designed and distributed.

\subsubsection{Phase 3a \& 3b: Action}

During these phases the participants from 1b) 'The Action focus group' and 2) 'The First evaluation group' worked together. 'The first evaluation group re- read and revised the content of the information letter's first draft. Further they gave verbal and written recommendations focused on language adaptations so that the content would be suited to FD receivers. After revision 2) 'The First evaluation group' terminated their involvement.

1b) "The Action focus group" produced the final version of the information letter, and distribute the information letters to all FD recipients i.e. 3) "The Second evaluation group" in the six municipalities chosen for this study. There was a telephone number given in the information letter so that the FD recipients could give oral feedback on the content of the letter and also to offer suggestions for subjects to be included in a future information letter. The letters $(\mathrm{n}=1700)$ were distributed during April 2011 together with their meal delivery.

\subsubsection{Phase 4: Evaluation}

The evaluation of the action was made during May 2011 using the verbal feedback from the FD receivers i.e. 3) "The Second evaluation group" ( $\mathrm{n}=29$ of 1700). The feedback was collected by one of the participants in $1 \mathrm{~b}$ ) 'The Action group'. Further, suggestions offered in the feedback were used as inspiration for the planning and production of the next information letters.

\subsection{Ethical considerations}

The study was performed in accordance with the Helsinki Declaration ${ }^{[22]}$ and has been examined by the regional ethical review board of Lund University (LU09/365). All participants consented to participate in the study after receiving detailed information about the study and confirmation of their right to discontinue their participation at any time without it having any consequences for them.

\section{Results}

\subsection{Phase 1: Look}

At the start of the AR cycle, the FD was described as a routinised logistic organisation chain. Meal boxes were distributed mainly by assistant nurses or taxi drivers who had very little exposure to ongoing education and development of their knowledge in nutrition. The themes that emerged during the SDM process were: the organisation of work, the need for continuous development of the FD recipient's and the involved professional's competence in nutrition and the collaboration between the various professional groups. 


\subsubsection{The organisation of work}

When the participants discussed the FD organisation, they stated that FD is a complex organisation and that the decisions made at the highest political and administrative level appear to somehow get lost on their way down through the hierarchy to the various organisation levels. They agreed that organisational support was a necessary part of the FD chain in order for everyone involved to have proper insight into the organisation as a whole, as well as into the individual responsibilities of all those involved. They stressed the importance of the highest level in the organisation having a good understanding of the complexity of FD. The participants felt that there was still a need for personnel with formal training in nursing and care and that the municipalities do not have enough nursing staff in relation to the number of care recipients. At the top level the politicians sitting on the committees for care and service for elderly people in their municipality did not, according to the participants, have enough insight into what happens within the organisation once they have passed down their decisions. The participants said that the meaning behind some of the decisions made at the top level was sometimes unclear and difficult to implement in practice. Furthermore, they agreed that the development of FD is dependent on support at a political level. This insight generated a discussion about how important it was to gain an overall picture of the effects of the FD organisation on the recipients. Constant organisational changes often resulted in additional stressful routines where staff had to perform FD-related tasks in less time. Furthermore, the participants described the FD organisation as a "living body" changing every day and with a high turnover of personnel which negatively influences continuity.

\subsubsection{The need for continuously developing the FD recipient's and professional's competence in nutrition}

It was stated that the FD recipients' and the professionals' knowledge about nutrition is insufficient and that there is need to continuously update and develop this knowledge. Some of participants noted that many elderly people believe that they did not need to eat as much as they did before and divide the portion of delivered food into two meals. Further the participants highlighted that proper knowledge of the FD routines is not known to many of the staff. Some participants said that the assistant nurses, who are nearest to the FD recipients, often have need for systematic information and knowledge concerning a specific FD recipient's general health status. The participants said that there was no continuous training for the FD personnel in the nutritional needs of elderly people and that there was a lack of information and feedback about the consequences of a malfunctioning FD service and further, that there were no clear general outlines. Furthermore, since there are no clear routines, assistant nurses did not know exactly what to do when screening for inadequate food intake, eating difficulties or weight loss among the FD receivers. The participants specifically illustrated situations where the personnel could identify deviations connected to the FD service but did not have routines, guide lines or policies to manage these deviations or to determine who had the overall responsibility for correcting any deviations: As one participant noted

"So after you have handed over the meal box to them in their own home you have no idea of what happens to it. And this is the group of people with possible difficulties as there is no one else involved to monitor their situation. This is the group we would like to reach, but under the present conditions it is very difficult."

\subsubsection{The collaboration between various professional groups}

It was assumed that knowledge about FD routines could facilitate collaboration with other involved personnel, especially where their work was regulated by different legislation. It was important for the participants to show that they do not need to feel that they have to have solutions to all of the identified problems; rather they have a need for dialogue with other involved care personnel. This insight illustrates that the care personnel need to think about strategies for solving problems together that emerge in daily practice. Variances in profession focused approach were viewed as being an obstacle to inter-professional collaboration. The participants especially highlighted the importance of flexibility and the desire to overcome obstacles. It was supposed that inter-professional collaboration between the personnel involved would promote the staff to have the FD recipient's best interest in mind. The participants noted that it should be in everyone's interest to build up collaboration, trust and respect for each other's knowledge and working tasks. The participants noted that many of the personnel do not have a clear picture of their own role or responsibility within the FD organisation. Continuity was described as important as this was necessary in order to build relationships between the home care personnel and the FD 
recipients. For example, the assistant nurses do not have a natural forum for dialogue with public home care officers regarding questions related to FD. Furthermore, the public home officers have no obligation to inform the district nurses regarding who receives FD. There was no collaboration between the different care personnel and the municipalities in the form of regular forums for dialogue and reflection around the experiences they have of the function of the FD chain. Also, collaboration could be improved if the involved personnel knew one another. That would make it easier for them to talk together and overcome difficulties.

\subsection{Phase 2: Think}

The findings were presented to the participants in 1b) "The Action focus group" in several ways including verbal and written presentation of the data raised during the 'look' phase. The findings encouraged many discussions enhanced by the introduction of three consequence analysis questions inspired by the CM. Reflection in and on practice was central to the discussions. The selection and determination of the development areas was encouraged and all participants had an active part in the process. This resulted in the choice of one improvement area that was to be focused upon, and this was the need for continuous development of FD recipient's and professional's competence in nutrition. One person, at the time, commented on the usefulness of the continuous, on-going development of knowledge. They motivated their choice of area by the fact that many possible development areas demand the involvement of a higher level of decision making in the FD organisation. Further they estimated that the choice of knowledge development is a part of their own professional framework and that they could work on it independent of high level decision makers. The participants found that an information letter appeared to be a suitable way to improve and spread knowledge related to nutrition. The process of planning focused on how the information should be designed and which way was the best to spread it. They determined that the information letters should be written in a manner appropriate for the FD recipients and that the text should be limited and concise.

\subsection{Phase 3: Act}

The participants chose to focus their action on an area they could influence and use the skills they possessed from their autonomous professional backgrounds. To ensure that the information was properly suited they made corrections in the text (see Figure 1). They specifically focused on tailoring the language toward the FD service recipient group. The information letter was to give advice concerning how the FD recipients could help themselves if they felt that they had a reduced appetite (see Table 2).

During April 2011, the ( $\mathrm{n}=1700)$ information letters were distributed, with the meals, to all FD recipients in the six participating municipalities in the southern part of the Sweden.

Table 2. Advice given in information letter number 1

\begin{tabular}{|l}
\hline What can I do myself? \\
Suggestions when you a lack appetite: \\
- Small portions rich in energy for breakfast, lunch, dinner and three snacks per day. \\
- $\quad$ Somewhat salty or sour snacks, such as pickled herring on bread, cheese with grapes or a cup of hot broth. \\
- It is preferable to use full-fat foods, such as whole milk (3\% fat), cream and butter, instead of reduced-fat products. \\
- A food box is intended to be a meal for one person, and a drink, bread and perhaps a salad should be added. \\
- It is important that you have something to drink with your meals. It is preferable to choose a drink rich in energy, such as \\
milk, juice, fruit syrup, low-alcohol beer or soda.
\end{tabular}

\subsection{Phase 4: Evaluation}

During May 2011, 29 out of the 1700 elderly persons i.e. 3) "The Second evaluation group" gave oral feed-back regarding the information letters. Based on the reactions of the FD recipients the evaluation of the action revealed a positive attitude 
towards the FD service on the part of the recipients and it was shown that the improvement in form of information letters was appreciated. Several suggestions for the content in future information letters were offered. Among the suggestions was a request for more information about taste, diabetic diet, appetite stimulation, flavouring the food, the consistence of meals related to chewing and digesting, proper and healthy snacks and the difference in size between energy enriched meals and ordinary meals. A positive point was that the information letters were also read by the assistant nurses responsible for distributing the meals. Many of them found that the content of the letters, although often short, gave them sufficient and valuable information. The evaluation resulted in two decisions by 'The Action focus group' firstly, to continue providing information letters twice a year, and secondly, to make the information available to all care personnel on the intranet.

\section{Discussion}

\subsection{Methodological considerations}

The findings from this study were evaluated in terms of trustworthiness, credibility, dependability, conformability and transferability ${ }^{[23]}$. Credibility and dependability were assured by presenting views from different participants in order to capture their various experiences. The SDM ${ }^{[19,20]}$ was used for collection and analysis of the data. The three reflection questions from $\mathrm{CM}^{[20]}$ were used for deeper analysis of the probable consequences with the chosen development area and which area should be given the most priority regarding focus. The capturing of the different experiences could be interpreted as a power since the participant groups built a "critical knowledge mass" ${ }^{[24]}$ which gave a bigger picture of their own practices and their intention to change and develop them. Through continuous dialogue the participants had confirmed the findings by recognising them in their everyday practice ${ }^{[25,26]}$. Conformability was assured by the use of the insight cards and the evaluation of the content of the information letters in the two steps. Transferability can be considered to be achieved by the way that the study was designed and the "action" approach can be transferred to different contexts in different countries. The findings can be considered to have been achieved if the present results can be recognised and transferred to comparable contexts ${ }^{[23]}$.

\subsection{Discussion of findings}

The 1a) "Identification group" for the development areas in the FD chain decided to withdraw their involvement after the last FG session, on the basis that they did not have sufficient time due to their working schedules. This can be seen as a weakness in this study. On the other hand, another motivated group, the 1b) "The action focus group", chose to continue and complete the work of the 1a) "The identification group". Their motivation to participate can be seen as a strength in the present study as it was their own decision to take part ${ }^{[27]}$. Other studies have shown that the bringing in of new participants during an on-going study can be seen as a way to enrich discussion and to expand views on the same problem ${ }^{[28,29]}$. On the other hand, it could be seen as a weakness that the new participants focused on other development areas that were nearest to their own interest and professional expertise. Other studies have shown that continual changes in the health care sector organisations are a natural part of the reality, which is also mirrored in research projects ${ }^{[30,31]}$. Taking the initiative, led by the study leader, the participants engaged in exploring issues of their practice in order to find out what they need for future development ${ }^{[16]}$. Meyer and Silow-Carroll described practice development as involving service users, health care providers, researchers and decision-makers to identify potential difficulties and what is needed to solve them, which she claimed as being central. She has pointed out that the success of practice development depends on how much can be learned by personal involvement. It can take time for new ideas to become embedded in practice which can be interpreted as creating a "bridge between theory and practice" ${ }^{[32]}$. The participants, with their unique knowledge of their own specific working situations, were the basis for the identification of development areas in the FD chain. The participants were motivated to solve problems that had arisen from their own practice. The intervention they chose to develop was FD recipient knowledge in nutrition, which was evaluated as being a proper and pedagogical alternative. Further it was an economic and time saving alternative for reaching many people. 
The improvement i.e. "action" in this study was the information letter distributed to FD recipients $(n=1700)$ in the six participating municipalities. Only 29 of the receivers chose to give verbal feedback on the content of the letters and suggest topics for the next information letter. This showed that there was a group of engaged elderly people who were positive and active towards obtaining information about their food and who also indicated that they wished to be an active part and have influence. Consequently, although the feedback from them was positive the opinions of the remaining 1671 elderly people remain unknown. One of the intentions of requesting feedback was to obtain voluntary and anonymous evaluations together with additional opinions needed for developing the content of future information letters. Winter et al found that participation is important for preparation of an action plan in relation to the specific context in the case of FD ${ }^{\text {[33] }}$. Continuous cycles of evaluation make it possible to gain more perspectives ${ }^{[34]}$. The FD recipient's viewpoints can be seen as a powerful vehicle for discovering new knowledge and to achieve a deeper understanding of their needs. Processing information and gaining new insights can clarify core difficulties that can be solved ${ }^{[20]}$ by focusing on detailed descriptions, explanations and critical consequence analysis of questions such as; what can be done to move on? What will happen if nothing is done? Which actions are considered to resolve the identified problem and what effects can be predicted? The dialogue on various strategies, including weaknesses and strengths continues until each action and the expected benefit of the chosen action are important enough to be discussed ${ }^{[35]}$. The process in this study was completed by a focus on what was important for the chosen action from the ethical, legal, economic, collaborative and organisational viewpoints in comparison with the results in the Rosengren et al. study ${ }^{[36]}$. Even though the participation of FD recipients was low, their contribution was a validation of the content of the information letters that had been distributed.

In the present study, the information letters were also appreciated by the personnel within the FD service who deliver the food and they also stated their belief that the information letters contained sufficient information to help the elderly. Further they suggested that the information letters should be accessible on the municipal intranet to all professionals involved in the FD chain. This gave the insight to the fact that the care personnel also needed the information that was provided in the information letters. This knowledge is consistent with results from other studies showing that food preparation and distribution related tasks had a low status and that the personnel who frequently had the responsibility for this service often had a low level of education ${ }^{[1,37]}$. Even though the 1992 reform was introduced 20 years ago, the municipalities have still not yet resolved the problems of ensuring that those personnel who are involved in the municipal FD service have the correct competence. It seems that the apparent organisational disinterest is related to the low status given to food supply related interventions. The same problem was shown in a study from the United Kingdom where foodrelated tasks were delegated to personnel with a low qualification level in care work ${ }^{[37]}$. The necessary knowledge to prevent possible consequences of, for example, insufficient food intake is missing which can be seen to weaken the whole FD chain ${ }^{[38]}$. In order to bring changes into practice, each individual among the involved personnel needs support from their management ${ }^{[39]}$. 'Actions' are created in the exchange between people, and consist of interactions characterised by sharing each other's thoughts and attitudes. Those who are planning and proceeding with actions for change in the FD chain need to consider the whole organisation, where relations, understanding and clarity are essential aspects. All these aspects can be vehicles for future changes in practice. Furthermore, the development of FD requires support at a political level. Politicians should be informed and aware about all of the levels of the FD service so that they understand the importance of FD and can ascertain whether their decisions are in fact implemented in practice in the way that they had intended. The findings in this study have implications for nursing, gerontology and the care for elderly people living in their own home. Further studies into the subject of municipal FD are required from the decision maker's perspective in order to explore whether their decision making fully takes into consideration the development needs in the FD chain.

\section{Conclusion}

This study has shown that systematic work with motivated and involved participants using an action research approach, the story dialogue method and the consequence analysis questions from the case method, can be beneficial and a starting point for the process of improvement in municipal FD practice. The main conclusion of the study was that systematic 
reflections over everyday practice can be the vehicle for future change of practice. The research process and the findings have implications for nursing, in the care for the elderly and gerontology.

\section{References}

[1] Dickinson A, Welch C, Ager L. No longer hungry in hospital: improving the hospital mealtime experience for older people through action research. J Clin Nurs. 2008; 17: 1492-502. PMid:18047573 http://dx.doi.org/10.1111/j.1365-2702.2007.02063.x

[2] Roy MA, Payette H. Meals-on-wheels improves energy and nutrient intake in a frail free-living elderly population. The journal of nutrition, health \& aging. 2006; 10: 554-60. PMid:17183428

[3] Pajalic Z, Persson L, Westergren A, Berggren V, Skovdahl K. The Experiences of Elderly People Living at Home Related to Their Receiving Meals Distributed by a Municipality in Sweden. Journal of Food Research. 2012b; 1: p68. http://dx.doi.org/10.5539/jfr.v1n1p68

[4] Pajalic Z, Persson L, Westergren A, Skovdahl K. Public home care professionals' experiences of being involved in food distribution to home-living elderly people in Sweden-a qualitative study with an action research approach. Journal of Nursing Education and Practice. 2012a; 2: p41. http://dx.doi.org/10.5430/jnep.v2n2p41

[5] Andersen M, Hedberg A. Food and health fact book from National Food Administration (in Swedish: Mat och hälsa faktabok från Livsmedelsverket). Uppsala: Livsmedelsverket; 2007.

[6] Raadu G. Statute handbook for personnel in health and care 2011 (in Swedish: Författningshandbok för personal inom hälso- och sjukvården. 2011). Stockholm: Liber; 2011.

[7] Øvretveit J, Hansson J, Brommels M. An integrated health and social care organisation in Sweden: creation and structure of a unique local public health and social care system. Health Policy (Amsterdam, Netherlands). 2010; 97: 113-21. PMid:20557972 http://dx.doi.org/10.1016/j.healthpol.2010.05.012

[8] Social services act. Stockholm: Ministry of health and social affairs, International secretariat; 1981.

[9] Rosen M, Haglund B. From healthy survivors to sick survivors - implications for the twenty-first century. Scandinavian Journal of Public Health. 2005; 33: 151-5. PMid:15823977 http://dx.doi.org/10.1080/14034940510032121

[10] Stringer, Genat. Action research in health. Upper Saddle River, N.J.: Merrill Prentice Hall; 2004.

[11] Meyer J. Evaluating action research. Age Ageing. 2000; 29 Suppl 2: 8-10. PMid:11109939

http://dx.doi.org/10.1093/oxfordjournals.ageing.a008104

[12] Bondas TE. Caritative leadership. Ministering to the patients. Nursing Administration Quarterly. 2003; 27: 249-53. PMid: 13677190

[13] Rycroft-Malone J. The PARIHS framework - a framework for guiding the implementation of evidence-based practice. Journal of nursing care quality. 2004; 19: 297-304. PMid:15535533 http://dx.doi.org/10.1097/00001786-200410000-00002

[14] Meyer JE. New paradigm research in practice: the trials and tribulations of action research. J Adv Nurs. 1993; 18: 1066-72. PMid:8370895 http://dx.doi.org/10.1046/j.1365-2648.1993.18071066.x

[15] Mur-Veeman I, Eijkelberg I, Spreeuwenberg C. How to manage the implementation of shared care: a discussion of the role of power, culture and structure in the development of shared care arrangements. J Manag Med. 2001; 15: 142-55. PMid:11547822 http://dx.doi.org/10.1108/02689230110394552

[16] Nilsson P. Enhance your workplace!: a dialogue tool for workplace health promotion with a salutogenic approach. Malmö: Institution of Clinical Science, Malmö, Lund University; 2010.

[17] Petersson P, Springett J, Blomqvist K. Telling stories from everyday practice, an opportunity to see a bigger picture: a participatory action research project about developing discharge planning. Health Soc Care Community. 2009; 17: 548-56. PMid:19840129 http://dx.doi.org/10.1111/j.1365-2524.2009.00854.x

[18] Westergren A. Näring och ätande: handbok för kommunal, sluten och öppen hälso- och sjukvård i Nordöstra Skåne. Hässleholm: Nätverket för Ätande och Näring, Nordöstra Skåne (NÄVER); 2008.

[19] Labonte RN, Feather J. Handbook on using stories in health promotion practice. Ottawa, Ont: University of Saskatchewan, Prairie Region Health Promotion reseach Centre. 1996.

[20] Egidius H. PBL och casemetodik : hur man gör och varför. Lund: Studentlitteratur; 1999.

[21] Morgan DL, Scannell AU. Focus group kit. Planning focus groups. 1998; 2.

[22] Saif M. World Medical Association Declaration of Helsinki: ethical principles for medical research involving human subjects. Jama. 2000; 284: 3043-5. http://dx.doi.org/10.1001/jama.284.23.3043

[23] Lincoln YS, Guba EG. Naturalistic inquiry. Beverly Hills, Calif.: Sage; 1985. 
[24] Pajalic Z, Persson L. Using Story Dialogue Method: inspired by the PAR approach, to identify and develop problem areas in food distribution to elderly people living at home in five municipalities in Sweden, Conference Paper, peer reviewed,. In: Conference Paper pr, Participatory Action Research and Action Learning, editor. Action Learning; Action Research Assosiation, ALARA, World Congress, Australia. 2010.

[25] Heron J. Co-operative inquiry: research into the human condition. London: SAGE; 1996.

[26] Pajalic Z, Persson L, Skovdahl K, Westergren A. Facilitating change, the decision-maker's view of municipality food distribution to elderly people living at home for development - a particaipatory action reserach study. Public Administration Research. 2012.

[27] Arnstein SR. A ladder of citizen participation. Journal of the American Institute of Planners. 1969; 35: 216-24. http://dx.doi.org/10.1080/01944366908977225

[28] Koch T, Selim P, Kralik D. Enhancing lives through the development of a community-based participatory action research programme. J Clin Nurs. 2002; 11: 109-17. PMid:11845746 http://dx.doi.org/10.1046/j.1365-2702.2002.00563.x

[29] Labonte R. Health promotion and empowerment: reflections on professional practice. Health Education Quarterly. 1994; 21: 253-68. PMid:8021151 http://dx.doi.org/10.1177/109019819402100209

[30] Bondas T. Nursing leadership from the perspective of clinical group supervision: a paradoxical practice. J Nurs Manag. 2010; 18: 477-86. PMid:20609052 http://dx.doi.org/10.1111/j.1365-2834.2010.01085.x

[31] Folkesson A, Petersen KA, Abrahamsson A, Blomqvist K, Petersson P, Pajalic Z, et al. Participatory practice in a Non Participatory world experiences and challenges of working in the health and social care sector in Sweden and elsewhere, Conference Paper, peer reviewed,. In: Conference Paper pr, editor. 2008.

[32] Meyer JA, Silow-Carroll S. Building on the job-based health care system: what would it take? Health Aff (Millwood). 2003; Suppl Web Exclusives: W3-415-25.

[33] Pajalic Z, Springett J, Dychawy-Rosner I. Ensuring a receptive context for participatory action research as a vehicle for change: the example of community assistance for the elderly in Sweden. Conference Paper, peer reviewed, Action Research Conference at Work Research Institute, Oslo, September 2007.

[34] Kralik D, Telford K, Campling F, Crouch P, Koch T, Price K. 'Moving on': the transition to living well with chronic illness. Aust J Holist Nurs. 2005; 12: 13-22.

[35] Koch T, Kralik D, Eastwood S, Schofield A. Breaking the silence: women living with multiple sclerosis and urinary incontinence. Int J Nurs Pract. 2001; 7: 16-23. PMid:11811342 http://dx.doi.org/10.1046/j.1440-172x.2001.00241.x

[36] Rosengren K, Bondas T, Nordholm L, Nordstrom G. Nurses' views of shared leadership in ICU: a case study. Intensive Crit Care Nurs. 2010; 26: 226-33. PMid:20599383 http://dx.doi.org/10.1016/j.iccn.2010.06.001

[37] Dickinson A, Welch C, Ager L, Costar A. Hospital mealtimes: action research for change? Proc Nutr Soc. $2005 ; 64: 269-75$. PMid:16048657 http://dx.doi.org/10.1079/PNS2005432

[38] Pajalic Z, Persson L, Westergren A, Skovdahl K. Public home care professionals' experiences of being involved in food distribution to home-living elderly people in Sweden-a qualitative study with an action research approach. Journal of Nursing Education and Practice. 2012; 2: p41. http://dx.doi.org/10.5430/jnep.v2n2p41

[39] McCormack B, Kitson A, Harvey G, Rycroft-Malone J, Titchen A, Seers K. Getting evidence into practice: the meaning of 'context'. J Adv Nurs. 2002; 38: 94-104. PMid:11895535 http://dx.doi.org/10.1046/j.1365-2648.2002.02150.x 